\title{
Delayed presentation of transposition of the great arteries with intact ventricular septum in an 8-week-old male infant at University College Hospital in Ibadan, Nigeria
}

\author{
A A Labaeka, MB BS, FMC Paed; OrcID 000-0002-9822-8560 \\ Paediatric Emergency Unit, Department of Paediatrics, University College Hospital Ibadan, Ibadan, Nigeria
}

Corresponding author: A A Labaeka (yemilabaeka2@gmail.com)

\begin{abstract}
Transposition of the great arteries is a rare type of critical congenital heart disease (CCHD) which commonly presents in the neonatal period and requires early diagnosis and intervention if the infant is to witness his/her first birthday. Here, we report a case of an 8-week-old term male infant who presented with a 2-day history of cough, breathlessness and cyanosis. Echocardiography confirmed dextro-transposition of the great arteries (d-TGA) with patent ductus arteriosus (PDA) and patent foramen ovale (PFO). The infant succumbed to cardiogenic shock due to late presentation and no access to definitive surgical intervention.

Keywords. congenital heart disease; transposition of great vessels; delayed presentation; developing countries.
\end{abstract}

South Afr J Crit Care 2021:37(1):37-39. https://doi.org/10.7196/SAJCC.2021.v37i1.460

Congenital heart disease (CHD) is one of the leading causes of birth defects in infants globally, and about a quarter of these children have a severe form of $\mathrm{CHD}$, known as critical congenital heart disease (CCHD). The condition requires surgery or catheter-based interventions within the first year of life. ${ }^{[1,2]} \mathrm{A}$ delay in the diagnosis, catheter intervention or definitive surgery for CCHD results in an increased risk of morbidity and mortality. ${ }^{[3]}$ CCHD includes hypoplastic left heart syndrome, pulmonary atresia, tetralogy of Fallot, total anomalous pulmonary venous return, transposition of the great arteries (TGA), tricuspid atresia and truncus arteriosus. ${ }^{[4]}$ TGA is a rare cyanotic CHD representing $7-8 \%$ of congenital heart malformations worldwide, ${ }^{[5]}$ and it represents about $2.1 \%$ of CHD seen in hospital-based data in Nigeria. ${ }^{[6]}$ The hallmark of the lesion is ventriculo-arterial discordance with the onset of symptoms and survival of the patients depends greatly on the degree of shunting occurring between the systemic and pulmonary circulation via the atrial septal defect, patent foramen ovale (PFO), ventricular septal defect, patent ductus arteriosus (PDA) and rarely through the aortopulmonary window. ${ }^{[7]}$ The majority of patients (60\%) have the aorta anterior to the right of the pulmonary artery (dextro (d)-TGA); nevertheless, others have their aorta anterior to the left of the pulmonary artery (levo (l)-TGA).

\section{Case report}

An 8-week-old term male infant presented to the emergency room with cough and breathlessness for about 2 days. He developed bluish discolouration of the tongue and poor feeding a few days after birth, however, the parents believed that it was inconsequential. The birth weight of the infant was $3000 \mathrm{~g}$ and he weighed $3700 \mathrm{~g}$ at presentation. He was in severe respiratory distress with severe hypoxaemia (oxygen saturation was 64\%) and fine crepitation in both middle and lower lung zones. His pulse was barely palpable with a capillary refill time of
5 seconds and a blood pressure of 65/30 mmHg. An electrocardiogram showed sinus rhythm with a P-pulmonale (right atrial enlargement) and the electrical axis showed right-axis deviation $\left(+100^{\circ}\right)$ along with right ventricular hypertrophy. Echocardiography (ECHO) confirmed d-TGA with PDO and PFO.

This patient would have benefitted from prostaglandin E1 (PGE1) infusion to keep the ductal patency and intracardiac mixing, but this medication is not readily available in Nigeria. We stabilised the patient in the emergency room; nevertheless, he remained critically ill and haemodynamically unstable. He was planned for a transfer to the nearest facility (about $70 \mathrm{~km}$ away), where he could have a catheter intervention, but this could not be accomplished because the family neither had health insurance coverage nor could afford out-of-pocket funding for the procedure.

Intravenous prostaglandin E could not be sourced within the country, so the clinical condition continued to deteriorate, and the child suffered multiple cardiopulmonary arrests and later succumbed to the illness 4 days after admission.

\section{Discussion}

Infants with d-TGA are usually born at term, while cyanosis is usually present within a few hours after birth. The clinical manifestation and the course of disease are largely dependent on the shunting between the pulmonary and systemic circulation. The present case had d-TGA with interventricular septum (IVS), although it presented late due to the high level of intracardiac mixing occurring through the PFO and PDA, and as the pulmonary blood flow increased, he developed congestive heart failure. This is similar to a case of a 33-day-old Turkmen boy reported by Hosseininjad et al..$^{[8]}$ in Iran, who had a d-TGA with a PFO and PDA, although our patient presented much later and did not recover from the cardiac collapse and eventually died. 
Studies have shown that a significant number of infants with CCHD are missed if screening is limited to routine clinical examination and antenatal ultrasonography. ${ }^{[2,3,9]}$

Routine pulse oximetry in a newborn before discharge from the hospital and birth centres can identify the majority of infants with CCHD. This simple, non-invasive, cost-effective and widely acceptable method can help in early identification of cyanotic CHD, and this may improve both the cardiovascular and neurodevelopmental outcomes if timely interventions are instituted. ${ }^{[3,9,10]}$ Early administration of PGE1 (alprostadil) within the first 48 hours after birth has been found to reduce early mortality in newborns with TGA. ${ }^{[1]}$ The patient needs to be commenced on PGE1 infusion at the rate of $0.05-0.1 \mu \mathrm{g} / \mathrm{kg} / \mathrm{min}$ as soon as the diagnosis of d-TGA is confirmed. This will help to maintain ductal patency and promote left-to-right intracardiac mixing, and thereby increase the level of oxygenated blood reaching the left atrium. ${ }^{[8]}$ The volume-overloaded left atrium is likely to shunt part of its content into the right atrium and improve the oxygen saturation of the aortic blood.

The outcome of the patient could have been favourable if oral or parenteral prostaglandin, Rashkind's septostomy and corrective cardiac surgery were available. Cardiac catheterisation and Rashkind balloon atrial septostomy is indicated for a patient who responds poorly to PGE1. The procedure is used to improve atrial level shunt and oxygenation. Improving atrial level shunting will allow the infant to gain more time for the definitive surgery, arterial switch operation (ASO). ${ }^{[8,12]}$

The ideal surgical correction for d-TGA-IVS is ASO or Jantene procedure, which aim to re-establish ventriculo-arterial concordance by detaching both great arteries and re-attaching them to the anatomically correct ventricles. The coronary arteries are also excised and re-implanted to the new aorta. This procedure is best performed within the first 4 weeks of life, when the pressure in the pulmonary vasculature is still high to prevent left ventricular involution. Once the pull pressures drop, the left ventricle becomes used to low pressure performance and involutes (i.e. loses the capacity to pump against high systemic pressures postoperatively). ${ }^{[12]}$

ASO (Senning's or Mustard) is recommended for infants with a late presentation - a two-way intra-arterial baffle is created in the top part of the heart using the patient's tissue or synthetic material to direct blood flow into the appropriate ventricles. Complications that may arise are related to baffle obstruction (superior and inferior vena cava syndrome) and heart failure. ${ }^{[12]}$ However, a review of 22 SA patients with TGA who had an intact ventricular ${ }^{[13]}$ septum reported that ASO is still a feasible and safe option for patients presenting late in developing countries if surgical resources are available. The outcome of those presenting as late as 9 weeks postnatally are similar to those presenting during the neonatal period. ${ }^{[13]}$ There is also evidence of successful late TGA repairs in some developing countries in children older than 1 year. ${ }^{[14]}$ The survival rate following surgery is as high as $85 \%$ in developing countries with the necessary resources, while a survival rate of $97 \%$ is reported in developed countries. ${ }^{[14]}$ The lower survival rate in developing countries has been associated with pre-operative comorbid conditions, infections and patients presenting late. ${ }^{[14]}$

The index patient presented with cardiogenic shock with poor systolic function, necessitating dopamine infusion. The caregiver could not afford the cost of seeking medical care in a private facility where the Rashkind balloon atrial septostomy procedure can be performed. The Nigerian healthcare system is poorly funded, and the country might not be able to meet the universal health coverage (UHC) by the year 2030 because of its present over-reliance on private out-of-pocket funding as the main source of health financing. Out-of-pocket expenditure still represents about $70 \%$ of the total health expenditure in Nigeria and only $5 \%$ of the Nigerian population (majority federal government employees) have a prepaid and risk-pooling health insurance scheme. ${ }^{[15,16]}$

Paediatric cardiac services in Nigeria are still grossly insufficient, with 33 paediatric cardiologists and 31 cardiac surgeons caring for a population of $\sim 90$ million children. ${ }^{[17]}$ An audit of the paediatric cardiac services in Nigeria reported that six out of 48 facilities have cardiac catheterisation services but only three use it for children, and six have facilities for open-heart surgeries. ${ }^{[17]}$ The majority of the paediatric cardiac surgical needs are met outside the country because the services are not readily available, while the few surgeries conducted within the country happen during periodic medical missions in collaboration with specialists and non-profit organisations (NPOs) from developed countries. ${ }^{[18,19]}$ Open-heart surgery is costly, there is a shortage of skilled workforce, inadequate infrastructure and laboratory support, and supply lines for necessary consumables are limited in Nigeria. ${ }^{[19]}$ In an effort to make open-heart surgery and interventional cardiology more readily available in the country, an Italian NPO, Bambini Cardiopatici nel Mondo (BCnM), in collaboration with the Nigerian Federal Ministry of Health and the University of Ibadan are building a Cardiovascular Disease Institute and a Cardiovascular Research and Training Centre. ${ }^{[19]}$ This effort will eventually help improve the delivery of cardiovascular healthcare services in the sub-region, making open-heart surgery and interventional cardiology more accessible and facilitating capacity building among specialists in this field of medicine.

The morbidity and mortality from CCHD can be reduced through early diagnosis by implementing routine pulse oximetry screening for all newborns, followed by diagnostic ECHO for all hypoxaemic newborns and early surgical interventions. ${ }^{[3,4]}$ In countries where resources for treatment are not available, efforts should be focused on paediatric cardiac palliative care to ensure the quality of life during endstage disease.

Incorporating the signs of CHD into the integrated management of childhood illness and training healthcare workers to identify these signs during the routine immunisation clinics, will also help with early identification and referral to a paediatric cardiologist before the infants become critically ill. The government needs to increase public financing for healthcare, expand the coverage of the present health insurance schemes to close to $100 \%$ and reduce out-of-pocket expenditure to less than $10 \%$. There is an urgent need to form a collaboration with paediatric cardiac centres in developed countries to facilitate capacity building and skills transfer, and to improve and standardise operating procedures.

\section{Conclusion}

Mortality from CCHD like TGA is still increasing in some developing countries where healthcare facilities are ill-equipped to readily offer either palliative or definitive surgery for this disease. The use of simple, costeffective and non-invasive methods like routine pulse oximetry screening for all newborns will facilitate early diagnosis and referral. There is a need for continuous advocacy and engagement with governments to improve investment in healthcare delivery through policy changes, universal health coverage and facilitating skills transfer, which will increase access to cardiac surgery and improve outcomes in children with CCHD. Collaboration between the governments of developing countries and NPOs should be fostered to facilitate teaching and training in complex surgical procedures. Good-quality paediatric cardiac palliative care should be the focus of treatment in resource-limited settings. 
Declaration. None.

Acknowledgements. None.

Author contributions. Sole author.

Funding. None.

Conflicts of interest. None.

1. World Health Organization (WHO). Congenital anomalies. Geneva: WHO, 2016. http://www. who.int/mediacentre/factsheets/fs370/en/ (accessed 24 June 2020).

2. Mahle WT, Newburger JW, Matherne GP, et al. Role of pulse oximetry in examining newborn for congenital heart disease: A scientific statement from the American Heart Association an American Academy of Paediatrics. Circulation 2009;120(5):447-458. https://doi.org/10.1161/ CIRCULATIONAHA.109.192576

3. Ewer AK. Pulse oximetry screening for critical congenital heart defects in newborn infants Should it be routine? Arch Dis Child Fetal Neonatal Ed 2013;99(1):F93-F95. https://doi. org/10.1136/archdischild-2013-303968

4. Harold JG. Screening for critical congenital heart disease in newborns. Circulation 2014;130(9):e79-e81. https://doi.org/10.1161/CIRCULATIONAHA.113.008522

5. Khairy P, Clair M, Fernandes SM, et al. Cardiovascular outcomes following the arterial switch operation for d-transposition of the great arteries. Circulation 2013;127(3):331-339. https://doi. org/10.1161/CIRCULATIONAHA.112.135046

6. Adebayo BE, Ogunkunle OO, Omokhodion SI, Luke RD. The spectrum of structural heart defects seen in children at the University College Hospital Ibadan. Nigerian J Cardiol 2016;13(2):130-135. https://doi.org/10.4103/0189-7969.187712

7. Charpie JR, Maher KO, Weber HS. Transposition of the great arteries. Medscape, 2017. https:// emedicine.medscape.com/article/900574-overview\#a5 (accessed 24 June 2020).

8. Hosseininejad SM, Hosseininejad FS, Esmaeili H, Aarabi M, Tabatabaei FS. A 33-day old infant with the transposition of the great arteries: A rare case report. Int J Pediatr 2018;6(10):8407-8411. https://doi.org/10.22038/IJP.2018.31799.2815
9. Mouledoux JH, Walsh WF. Evaluating the diagnostic gap: Statewide incidence of undiagnosed critical congenital heart disease before newborn screening with pulse oximetry. Paed Cardio 2013;34(7):1680-1686. https://doi.org/10.1007/s00246-013-0697-1

10. Powell R, Pattison HM, Bhoyar A, et al. Pulse oximetry screening for congenital heart defects in newborn infants: An evaluation of acceptability to mothers. Arch Dis Child Fetal Neonatal Ed newborn infants: An evaluation of acceptability to mothers. Arch D

11. Domínguez-Manzano P, Herraiz I, Mendoza A, et al. Impact of prenatal diagnosis of transposition of the great arteries on postnatal outcome. J Matern Fetal Neonat Med 2017;30(23):2858-2863. https://doi.org/10.1080/14767058.2016.1265934

12. Kliegman R, Stanton B, St. Geme JW, Schor NF, Behrman RE, Nelson WE. Nelson Textbook of Paediatrics. Philadephia: Elsevier, 2016.

13. Edwin F, Kinsley RH, Brink J, Martin G, Mamorare H, Colsen P. Late primary arterial switch for transposition of the great arteries with intact ventricular septum in an African population. for transposition of the great arteries with intact ventricular septum in an African population.

14. Schidlow DN, Jenkins KJ, Gauvreau K, et al. Transposition of the great arteries in the developing world. Surgery and outcomes. J Am College Cardiol 2017;69(1):43-51. https://doi.org/10.1016/j. jacc.2016.10.051

15. Onwujekwe O, Hanson K, Uzochukwu B. Examining inequalities in incidence of catastrophic health expenditures on different health care services and health facilities in Nigeria. PLoS ONE 2012;7(7):e40811. https://doi.org/10.1371/journal.pone.0040811

16. Lawanson AO, Olaniyan O. Health expenditure and health status in Northern and Southern Nigeria: A comparative analysis using national health account framework. Afr J Health Econ 2013;2:31-46 https://doi.org/10.35202/AJHE.2013.2103

17. Ekure EN, Sadoh WE, Bode-Thomas F, et al. Audit of availability and distribution of paediatric cardiology services and facilities in Nigeria. Cardiovasc J Afr 2017;28(1):54-59. https://do org/10.5830/CVJA-2016-05

18. Ekure EN, Okoromah CN. In-hospital outcome of children referred for cardiac surgery abroad from developing country. Nig J Paediatrics 2009;36:80-86.

19. Ogunkunle OO, Adebayo BE, Famosaya A, Omokhodion SI. Initial experience with interventiona and definitive solutions for structural heart diseases in resource-challenged setting. $\mathrm{Nig} \mathrm{J} \mathrm{Cardiol}$ 2020;17:67-70. https://doi.org/10.4103/njc.njc_31_19

Accepted 10 December 2020. 